\title{
Promoting Best Practice and Safety Through Preprinted Physician Orders
}

\author{
George Ehringer, MD; Barbara Duffy, RN, LHRM, MPH
}

\section{Abstract}

Defining how preprinted physician orders are developed within a hospital has the potential to positively affect care, services, reimbursement, safety, and patient outcome. When they are well designed, preprinted physician orders have the potential to improve interdisciplinary integration in care, promote accurate communication, and reduce variation by combining pertinent reminders, safety alerts, and "best practice" into a just-in-time process. Whether in electronic or paper format, preprinted physician orders can transform evidence-based knowledge into practice.

\section{Introduction}

Because physicians' orders for hospitalized patients have the unique characteristic of affecting and bringing together multiple diverse disciplines and processes, designing orders is both an art and a science from which all medical disciplines and patients can benefit. Although physicians may rightfully feel they are responsible for the content of orders, clear, accurate, and concise communication requires a coordinated, team approach. Through multidisciplinary involvement, preprinted physician orders (both paper and electronic) provide an opportunity to involve a broad range of perspectives in decisions about the care of a single patient.

In addition to being available for immediate use for commonly performed interventions, other advantages of well designed, preprinted orders include:

- Continued, coordinated, and integrated care by communicating "best practice" through multiple disciplines, levels of care, and services.

- Modified practice through educated staff and physicians regarding evidence-based care.

- Reduced variation and unintentional oversight through standardized formatting and consistent style in a legible and clear presentation.

- Enhanced time-saving work flow with pertinent instructions that are easily understood, intuitively organized, and suitable for direct application to current information-management systems.

- Reduced potential for medication errors through integrated safety alerts and reminders.

- Increased utilization of continued outpatient services post-discharge via appropriate reminders.

- Convenient access to relevant references and other information.

- Simplified data abstraction via indicators for Joint Commission Core Measures and National Patient Safety Goals. ${ }^{1}$ 
- Improved documentation for utilization and reimbursement purposes.

- Comprehensive orders that clearly communicate directions and reduce unnecessary calls to physicians for clarifications and questions.

Whether they are printed on paper or available for electronic access, development and implementation of well designed, preprinted physician orders requires engineering, education, and enforcement. Because physician orders exist at the intersection where multiple disciplines and services (e.g., case and risk management) converge, they are the ideal medium by which to address concerns pertaining to reimbursement, utilization, patient safety, and quality measures. Orders are the initial means that enable physicians to communicate with a variety of interdisciplinary hospital caregivers, and they represent the starting point for action and care. In the health care environment, nothing goes forward without calling on the assistance of and providing direction through physician orders.

Although research supports the effects of electronic reminders and computerized physician (or provider) order entry (CPOE) on patient care, ${ }^{2}$ the present article describes our efforts (some of them through trial and error, some supported by research) to define and refine preprinted physician orders (including paper-based models) that improve interdisciplinary integration and accurate communication, while reducing unnecessary variation. We offer ideas about applying elements and concepts of computerized clinical decision-support systems to paper-based models and considering application of paper-based order structures and criteria to the electronic physician order format.

Advances in technology allow preprinted physician orders to have flexibility and the ability to rapidly adjust and adapt to changes in individual hospital processes, patients, and available services. Preprinted orders offer a low cost and simple-to-implement opportunity to affect the functional organization of the health care process, quality of care, and ultimately, patient outcome.

\section{The Essence of Preprinted Physician Orders}

Creating any well designed physician order requires considerations that can be broadly broken down into the headings of engineering, education, and enforcement.

\section{Engineering}

Engineering refers to the most mechanical aspects of developing orders, including items such as content, format, and medication safety.

- Content ensures that orders are comprehensive, correct, and coordinated. Content may include information beyond what the physician might initially consider, such as venous thromboembolism prophylaxis and influenza vaccination screening.

- Format defines type and layout considerations that can make orders easier to read and comprehend. Elements of format include font, point size, white space, use of symbols, capitalization, and adequate space for handwritten entries. Format consistency is improved through attention to standardizing usage, punctuation, arrangement, design, and other factors. 
- Medication safety recommendations call for presenting medication information or instructions in a clear and consistent manner, which is very important for all aspects of physician orders. Advice from the Institute for Safe Medication Practices, the United States Food and Drug Administration, and others as it pertains to writing medication orders is presented later in this paper.

\section{Education}

Preprinted physician orders offer an excellent opportunity to provide and implement timely instructions to physicians, staff, and patients regarding "best practice" and general patient safety. This information might involve attaching pertinent printed patient education material to the orders for easy and timely distribution by the nurse to the patient. It might also involve printing appropriate reference information on the reverse side of paper orders (or offering an appropriate Internet link to this information in CPOE). This information might include a listing of applicable formulary medications and dosages, indications of appropriate antibiotic use, evidence-based algorithms to guide care and decisionmaking, and a list of reportable core measures for a particular diagnosis. Education regarding safety, "best practice," infection control, and outpatient referrals might also be performed through well placed reminders and alerts within the orders.

\section{Enforcement}

Managing changes in orders, keeping them current to reflect "best practice," and ensuring that only the most current versions are available and in use offer a different, but related, set of challenges. Without some control of the mechanics of and access to order changing, the potential increases for miscommunication, unacceptable variations, and error. Methods for guiding process standardization are discussed later in this paper.

\section{Engineering: Content}

Generally, orders begin with content. In other words, the physician writes or creates orders for a specific procedure, diagnosis, care, or admission. Examples of content criteria are shown in Table 1. 


\section{Table 1. Examples of content criteria}

\begin{tabular}{ll}
\hline Criteria & \multicolumn{1}{c}{ Examples or clarification } \\
\hline $\begin{array}{l}\text { 1. Do the orders reflect current } \\
\text { "best practice"? }\end{array}$ & $\begin{array}{l}\text { Is there evidence to support the orders? Such evidence may } \\
\text { come from recently published literature, research, } \\
\text { association guidelines, or recommended practices. }\end{array}$ \\
\hline
\end{tabular}

Do orders include all likely needs, e.g., other services, other disciplines, and discharge planning as appropriate?

2. Are orders comprehensive and do they consider other disciplines?
For example, some physicians might not consider the following when admitting a patient for a diagnosis of dehydration:

$\checkmark$ Screen patient for smoking history. RT to provide smoking cessation counseling if patient has smoked within 12 months. (Performance measure)

Sometimes it may be necessary to obtain the patient's weight before the pharmacy can determine proper drug dosing.

If hospital process requires scanning paper orders to the pharmacy, it would be helpful to including the following information (for the nurse to complete) within the paper/scanned order. An order might read as follows:

$\checkmark$ Obtain patient weight.

Patient weight:

$\square$ actual $\square$ estimated

$\square$ pounds $\square$ KILOgrams

Do orders include the following statement? "Strike through entire line to cancel a prechecked order."
3. Are automatic orders prechecked to reduce the possibility of their being overlooked?

4. Are performance measures indicated, e.g., Joint Commission Core and National Hospital Quality measures? ${ }^{1}$

5. Is the inclusion of National Patient Safety Goals (NPSG) considered? ${ }^{3}$

6. Is consideration given to infection control measures? $\checkmark$ Screen patient for pneumococcal vaccination history and candidacy.

Administer Pneumovax ${ }^{\circledR} 0.5 \mathrm{~mL}$ IM into deltoid as appropriate prior to discharge. (Performance measure).

$\checkmark$ Verify (through read back) critical lab values and notify physician immediately. (Safety measure)

Provide vital sign parameters re: when to notify the physician and when to initiate a rapid-response team call for immediate patient assessment. (Safety measure)

$\checkmark$ Prep and clip hair of right groin area. Do not shave.

$\checkmark$ Start IV antibiotic of cefazolin (Ancef ${ }^{(B)} 1 \mathrm{~g}$ no more than 60 min prior to incision time. (Performance measure)

$\checkmark$ Cefazolin (Ancef $\left.{ }^{\circledR}\right) 1 \mathrm{~g} \mathrm{IV}$ q8h for up to $24 \mathrm{~h}$ after surgery end time. Start upon arrival at PACU.

Surgery end time (required for pharmacy to schedule doses). (Performance measure) 
Table 1. Examples of content criteria (continued)

\begin{tabular}{ll}
\hline Criteria & \multicolumn{1}{c}{ Examples or clarification } \\
\hline $\begin{array}{l}\text { 7. Are listed medications and } \\
\text { equipment available at your } \\
\text { facility? }\end{array}$ & Check medications against the formulary. \\
& Make sure materials management or bioengineering is able \\
& to support equipment items. \\
\hline & Clearly indicating inpatient, outpatient, or observation status \\
can affect reimbursement. When feasible, include orders \\
such as: \\
- Admit as inpatient to \\
- In some cases. it maybe preferable to provide a forced \\
$\begin{array}{l}\text { 8. Are considerations given to } \\
\text { coding and reimbursement } \\
\text { documentation requirements? }\end{array}$ \\
option for the physician to complete, such as: \\
\\
- Patient status: $\square$ Inpatient $\square$ Outpatient \\
$\square$ Observation status. \\
- Likewise, the following statement may be very helpful in \\
ED orders: "May use nursing documentation for coding."
\end{tabular}

\section{Engineering: Format}

As the population of health care providers ages, it becomes ever more important to make the printed words they rely on to care for their patients as easy to read as possible. Table 2 summarizes several ways to accomplish this.

\section{Table 2. Improving legibility of printed documents}

\begin{tabular}{ll}
\hline Criteria & \multicolumn{1}{c}{ Examples or clarification } \\
\hline & A nonserif font (e.g., Arial 12-point) is recommended, \\
1. Is the print simple to read? & $\begin{array}{l}\text { more likely fo occur when faxed copies are not as clean or } \\
\text { legible as they could be. }\end{array}$ \\
\hline & $\square$ Nothing by mouth after midnight. ...But no diet was \\
& ordered before midnight. \\
& $\square$ Elevate head of bed as appropriate. No indication why, \\
& when, or how high. \\
& $\square$ Advance diet as tolerated. Inadequate guidance for the \\
2. Are instructions complete, & nurse to determine the proper action. \\
unambiguous, and clear? & Likewise, write out "Left" and "Right." The letters $L$ and $R$ \\
& may be interpreted as "Lower" or "Liter" and "Raise," \\
& respectively. \\
\hline
\end{tabular}




\title{
Table 2. Improving legibility of printed documents (continued)
}

Criteria
3. Is the use of symbols kept to a
minimum? Be wary of letters and
numbers that may be easily
confused or misinterpreted.

\author{
Examples or clarification
}

- Do not use the symbols "<" and ">". Instead, write out "less than" and "more than."

- Slashes (/) can be easily misread as the number one. If a slash must be used, provide a space before and after the slash; e.g., "20 mg / $500 \mathrm{~mL}$ "; or write "per" in place of the slash, e.g., $20 \mathrm{mg}$ per $500 \mathrm{~mL}$.

- The letter "O" can be misread as the number zero. Writing out "one" and "zero" can sometimes reduce confusion.

- Lower case $L$ (I) can be misread as the number one or the capital letter I; e.g., lodine (iodine) can easily be confused with lodine, or Lodine ${ }^{\circledR}$ (etodolac).

- To reduce confusion between certain look-alike letters, consideration may be given to using lower case "i" and upper case "L". This may create issues with "tall-man lettering"; e.g., "miLLiLiTERS" and certain drug names in all capital letters: "iNSULiN".

\section{Are attempts made to remove or reduce look-alike or sound-alike items?}

5. Is "tall-man lettering" used for all look-alike names and words?

6. Do the orders include a space for physician ID\# next to the signature line?

7. Are upper case letters used appropriately?
For example, "BNP" vs. "BMP". Instead, write out "brain natriuretic peptide" (or "BN peptide") and "basic metabolic panel".

"Tall-man lettering" can also apply to words like "eAr" and "eYe". ${ }^{5}$

Including an identification number on the signature line helps identify the physician:

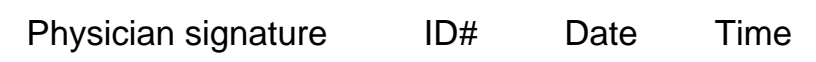

When lower case letters are used, "PRN" can be easily misread as "pm". The best option is to write out "as needed" or place "PRN" in all capital letters.

Likewise, while not entirely chemically proper, "KCL" has been read as "KCl" when all caps are not used, as is technically correct.

"STAT" may be placed in all capital letters for emphasis.

Orders written on the reverse side of sheets are often overlooked. The reverse sides of orders are best used only for references, additional information, etc.

Further consideration should be given to the way orders look and feel. This involves standardizing the sequence in which information is presented on the order sheet or screen. This method can also be utilized on paper orders to help prepare staff for the transition to an upcoming CPOE implementation. For example, orders may be consistently grouped under headers, as appropriate, in the order shown in Table 3. 


\section{Table 3. Optimal presentation of orders}

\begin{tabular}{|c|c|}
\hline Order group & Examples \\
\hline \multirow{2}{*}{ Admission status } & $\begin{array}{l}\text { Inpatient, outpatient, observation status. (These options may be } \\
\text { adjusted, depending upon the type of order.) }\end{array}$ \\
\hline & $\begin{array}{l}\text { Other aspects of admission status include full code, no code, comfort } \\
\text { care, isolation status, diagnosis, and the procedure to be performed. }\end{array}$ \\
\hline Nursing orders & Wound care, Foley catheter, activity orders, vital signs. \\
\hline Dietary & Diet orders, tube feedings, nothing by mouth. \\
\hline IV fluid & Type, rate, amount. \\
\hline Medications & $\begin{array}{l}\text { By mouth, IV, IM, topical, scheduled, PRN, etc. Medication options, } \\
\text { when listed on the orders, are generally listed, first by the most } \\
\text { commonly used drug and dose, and then by dose size (smallest to } \\
\text { largest) and dosing frequency (lowest to highest). }\end{array}$ \\
\hline Cardiopulmonary & Echocardiograms, respiratory treatment. \\
\hline Laboratory & Blood work orders. \\
\hline Radiology / Imaging & $\begin{array}{l}\mathrm{CT}, \mathrm{MRI} \text {, chest } \mathrm{x} \text {-ray, and a prompt to include the reason } \\
\text { for each test. }\end{array}$ \\
\hline Therapy & Physical therapy, speech therapy, social worker. \\
\hline Consults & $\begin{array}{l}\text { Other physicians, case management, wound care nurse, nutritional } \\
\text { evaluation, chaplain, et al. }\end{array}$ \\
\hline Patient education & $\begin{array}{l}\text { Stroke or CHF education booklets, diet education, diabetes care, } \\
\text { ostomy training. }\end{array}$ \\
\hline $\begin{array}{l}\text { Venous thromboembolism } \\
\text { prophylaxis }\end{array}$ & $\begin{array}{l}\text { Sequential compression devices for bilateral lower extremities; } \\
\text { anticoagulation therapy. }\end{array}$ \\
\hline Vaccination status & Screening and orders to vaccinate as appropriate. \\
\hline
\end{tabular}

Formatting also involves consistency in expressing weights and measures. When abbreviations are used, they should follow the U.S. Pharmacopeia (USP) standard abbreviations for dosage units. The most common abbreviations are shown in Table $4 .^{6}$

In addition, formatting should consider wording to assist unit secretaries in putting orders into hospital-specific information systems. For example, an order to request smoking cessation education for a patient might read as follows:

$\checkmark$ RT for smoke cessation if patient has smoked within the past 12 months. (Performance measure).

All preprinted orders should use the same template, which includes specified areas for:

- Date.

- Orders.

- Name of orders.

- Date of latest review. 
- Facility name.

- Allergies or adverse reactions.

- Pharmacy code (if used).

- Patient identification information.

- Page number (e.g., page 1 of 3).

- Appropriate barcode if applicable.

Depending on the information system used within a hospital, the pharmacy may be able to code orders for quick and accurate entry into their system. Placing this code under the name of the orders (e.g., "POLUM" printed under the name of post-op lumbar surgery orders 0707) saves order entry time in the pharmacy. Additionally, to avoid potential inconsistencies, if patient allergies or adverse reactions are handwritten entries on paper order tools, they would be listed only on page 1 of multipage paper orders. Ample space should be provided to describe these reactions.

\section{Engineering: Medication Safety}

Perhaps nowhere is safety more important than in orders pertaining to medications. Table 5 lists some common concerns regarding safety and medication orders.

Table 5. Common concerns regarding safety and medication orders

\begin{tabular}{ll}
\hline Criteria & \multicolumn{1}{c}{ Examples or clarification } \\
\hline & $\begin{array}{l}\text { - } \\
\text { habreviations are time-saving measures when } \\
\text { handwriting orders. But, since preprinted orders can be } \\
\text { readily reproduced by electronic or printed means, }\end{array}$ \\
$\begin{array}{l}\text { 1. Do the orders limit } \\
\text { abbreviations to a minimum } \\
\text { and never use unapproved } \\
\text { abbreviations (e.g., QD or U)? }\end{array}$ & $\begin{array}{l}\text { used rarely. Abbreviated medication names should } \\
\text { be avoided. }\end{array}$ \\
& $\begin{array}{l}{ }^{7} \\
\text { - The risk of dosing errors can also be reduced by avoiding } \\
\text { the use of leading zeros before a decimal point and the } \\
\text { use of trailing zeros after a decimal point. }\end{array}$ \\
\hline
\end{tabular}

2. Are medication orders numbered?

This is not a recommended practice because the order number may be confused with the medication dose. 


\section{Table 5. Common concerns regarding safety and medication orders (continued)}

Criteria

3. Are all medications listed together under the title, "Medications"?

\section{Examples or clarification}

- This makes it easier to take these orders off and lessens the possibility of overlooking a medication order.

- It also helps the pharmacy in completing the medication administration record. (Remember to include "Saline flush every 8 hours and as needed to maintain patency" under "Medications" when a nursing order calls for a saline lock.)

Blanket orders can be confusing or imprecise and are not permitted, for example:

4. Are blanket or multiple-range orders used? (e.g., 1-2 tablets every 3-4 hours)
- "Continue previous medications" is never allowed.

- A multiple-range order should read " $\square$ morphine 1-2 mg IV every 3-4 hours as needed for moderate pain."

5. Do orders always list indications for PRN medications?

Listing the indication helps verify that the medication and dosing are correct. ${ }^{6}$

- A listing of look-alike medication names can be found at: www.fda.gov/cder/drug/MedErrors/nameDiff.htm. ${ }^{6,9,10}$

6. Is "tall-man lettering" used for look-alike medication names?

- "Tall-man lettering" can also be useful when spelling out worlds like "TEAspoon" and "KILOgram."

- Write "warfarin Na," NOT "Na warfarin," which may be read as "No warfarin."

7. If salts are used as part of medication names, do they follow the drug name?

- Better yet, do not use the salt as part of the medication name unless necessary; or spell out the name of the salt, e.g., "warfarin sodium.."

8. Do orders use the word "thousand" and "million" for large doses?

Write "1 million units" or "150 thousand units" rather than $1,000,000$ or 150,000 units

9. Do orders use commas for dosage numbers expressed in thousands?

10. Is there a space between the name of the medication and the dosage or unit of measure?

Write "5,000," NOT "5000". ${ }^{6}$

Write "propranolol 20 mg," NOT "propranolol20mg," which may be misread as $120 \mathrm{mg}^{6}$

For example, many medications contain acetaminophen.

11. Do orders contain a total dose warning for appropriate medications?

The warning, "Maximum total dose of acetaminophen not to exceed 4,000 mg per 24 hours" (for adults)" should be included in all orders with any medication(s) containing acetaminophen. 


\section{Table 5. Common concerns regarding safety and medication orders (continued)}

\begin{tabular}{|c|c|}
\hline Criteria & Examples or clarification \\
\hline $\begin{array}{l}\text { 12. Do paper orders contain a } \\
\text { medication warning above the } \\
\text { physician signature line as } \\
\text { appropriate? e.g., "Adverse } \\
\text { Reaction I Allergy Alert! } \\
\text { These orders contain [aspirin, } \\
\text { NSAIDS, antibiotic, narcotic, } \\
\text { sulfonamides or MAO] } \\
\text { medications?" }\end{array}$ & $\begin{array}{l}\text { This warning serves as a reminder for physicians to check } \\
\text { adverse reactions or allergies prior to signing preprinted } \\
\text { orders. }\end{array}$ \\
\hline $\begin{array}{l}\text { 13. Do medication orders include } \\
\text { drug name, strength, dose, } \\
\text { route, and frequency? }\end{array}$ & $\begin{array}{l}\square \text { Furosemide }\left(\text { Lasix }^{\circledR}\right) 40 \mathrm{mg} \text {. Take one tablet by mouth } \\
\text { one time daily. }\end{array}$ \\
\hline $\begin{array}{l}\text { 14. Are generic and trade names, if } \\
\text { applicable, used? }\end{array}$ & $\begin{array}{l}\text { - Just as patients are identified in two ways, so should } \\
\text { medications. List the generic name first followed by trade } \\
\text { name in parentheses; e.g., bumetanide }\left(\text { Bumex }^{\circledR}\right) \text {. } \\
\text { - Some literature recommends placing the trade name in } \\
\text { ALL CAPS. } \\
\text { - Consider including the drug's purpose for high-risk, easily } \\
\text { confused, or problematic drugs. }\end{array}$ \\
\hline
\end{tabular}

15. Do medication orders contain criteria for determining the route of administration to be used, if multiple routes are Give IV until patient is able to tolerate liquids by mouth. possible?

16. Are medication doses written in MILLIgram ( $\mathrm{mg}$ ) when possible and not just in tablets or milliLITER $(\mathrm{mL})$ doses?

$\checkmark$ Acetaminophen (Tylenol) $500 \mathrm{mg}$. Take one tablet by mouth every 6 hours as needed for mild pain.

17. Is a timeframe included for IV bolus and IV push medications?

$\checkmark$ Diazepam (Valium) $5 \mathrm{mg} / \mathrm{mL}$. Give $5 \mathrm{mg}$ IV push, over at least 1 minute, every 4 hours, as needed for muscle spasm.

18. Do the orders refer to all medications (from different specialists, OTC, etc.) as appropriate?

$\checkmark$ Refer to Medication Reconciliation Sheet for further medication orders. (Safety measure)

- As appropriate, reconciliation of medications is a National Patient Safety Goal.

- The schedule (and stacking) of medications can contribute to falls in the elderly.

19. Do the scheduled times for medication administration promote patient safety?

- Something as simple as changing scheduled medication times for every-12-hour diuretic medications from 9 am and $9 \mathrm{pm}$ to $9 \mathrm{am}$ and $5 \mathrm{pm}$ can decrease nighttime falls in patients trying to get to the restroom. 


\section{Table 5. Common concerns regarding safety and medication orders (continued)}

\begin{tabular}{ll}
\hline Criteria & \multicolumn{1}{c}{ Examples or clarification } \\
\hline & - $\begin{array}{c}\text { Consider look-alike and sound-alike words within your } \\
\text { cultural population. }\end{array}$ \\
$\begin{array}{l}\text { 20. Do orders consider potential } \\
\text { errors within the local cultural } \\
\text { setting? }\end{array}$ & $\begin{array}{l}\text { Perhaps most prevalent in the outpatient setting, a } \\
\text { patient received a massive medication overdose when a } \\
\text { Spanish-speaking caregiver interpreted "once a day" as } \\
\text { "eleven a day." (The Spanish translation of "eleven" is } \\
\text { "once.") }\end{array}$ \\
\hline
\end{tabular}

Medication safety also includes alerts and reminders as appropriate to the patient's condition or to the medications or treatments being ordered. Studies have concluded that electronic alerts favorably influence physician practice and patient outcomes. ${ }^{13,14,15,16,17}$

Reminder systems can easily apply to paper orders and may involve separate checked $(\square)$ or unchecked $(\square)$ orders; or they may be part of an order. Examples include the following:

$\checkmark$ Hold HEPARIN and enoxaparin (Lovenox ${ }^{\circledR}$ ) while the epidural catheter is in place.

$\checkmark$ Do not give narcotics by mouth, IV, IM, or by transdermal patch until epidural is discontinued.

$\square$ Enoxaparin (Lovenox ${ }^{\circledR}$ ) $1 \mathrm{mg} / \mathrm{kg}$ subcutaneously every 12 hours $\mathrm{x}$ doses. (Pharmacy to monitor and adjust dose if patient weight is equal to or greater than $180 \mathrm{~kg}$ and / or creatinine clearance less than $30 \mathrm{~mL} /$ minute. Hold if patient is going to surgery within 24 hours.)

$\square$ Clopidogrel $\left(\right.$ Plavix ${ }^{\circledR}$ ___ _ mg by mouth $\mathrm{x} 1$ dose. (Hold if going to Cath Lab or CABG within 5 days)."

- Do NOT mix glargine (Lantus ${ }^{\circledR}$ ) with other INSULINs.

- Administer pneumococcal and influenza vaccines in separate arms.

- Inform surgeon if the patient has taken warfarin (Coumadin), clopidogrel (Plavix ${ }^{\circledR}$ ), or overthe-counter supplements of feverfew, garlic, ginger, ginkgo, vitamin E, kava kava, St. John's wort, or valerian within the past 5 days. (Pre-op testing order.)

Two particularly high-risk, commonly used drugs deserve special attention. There have been several publicized errors involving the accidental switching of HEPARIN and INSULIN. ${ }^{18}$ As a result of this risk (and also because these two medications have no secondary names) and to bring more attention to the names, it is recommended that ALL CAPS be used when writing out these medications. 


\section{Education}

All physician orders provide an excellent opportunity to educate others regarding "best practice" and safety through alerts, reminders, references, attached information, and indicators. Examples to consider as appropriate include the following:

\section{Patient Safety}

Integrating reminders into the process increases effectiveness; ${ }^{15,17,19}$ for example:

- This drug may increase risk of falls.

- Do not use a zero AFTER a decimal; always use a zero BEFORE a decimal.

- $\quad$ Do not use the following abbreviations: U; OD; QN; SS; ug; QD; QOD; MS; MS04; MGS04. INSTEAD, WRITE OUT INTENDED MEANING.

- Provide an indication for each PRN order. (Place this at the top of each order sheet or screen for quick reference.)

Ketorolac $\left(\right.$ Toradol $^{\circledR}$ ) 30 mg IV every 6 hours. (If patient is 65 years or older, reduce dose to $15 \mathrm{mg}$ IV every 6 hours.) Notify physician if creatinine is greater than $1.8 \mathrm{mg} / \mathrm{dL}$ before giving this drug.

Telephone Order Read-Back. (Safety measure) Place this under the nursing signature line.

\section{"Best Practice"}

Indicators are used to provide notice and awareness of core measures and "best practice"; for example:

Either an ACEI or ARB is prescribed at discharge unless there is a contraindication or reason for not prescribing EACH. (Performance measure)

If vancomycin is ordered, please indicate reason:

Beta-lactam allergy

Known colonization with MRSA

Nursing home-stay within past year

Chronic wound care or dialysis

Other (Performance measure)

$\checkmark \quad$ Give the patient / family "Living with Heart Failure” education booklet; instruct on diet, activity, medications, weight monitoring, followup, signs and symptoms (and what to do if they return), smoking cessation / avoidance, and hand washing. (Performance measure) 
$\checkmark \quad$ Beta-blocker for left ventricular systolic dysfunction

Contraindications:
Allergic
Bradycardia (less than $60 \mathrm{bpm}$ )
$2^{\text {nd }}$ or $3^{\text {rd }}$ degree heart block
Systolic blood pressure less than $90 \mathrm{~mm} \mathrm{Hg}$
Other
(Performance measure)

\section{Referrals to Outpatient Services}

Preprinted orders also provide the opportunity to educate and remind health care providers of the continuation of optional services provided outside of the hospital. For example:

Outpatient diabetes education postdischarge. Unless the patient has another preference, fax this order sheet to Memorial System Diabetes Center at 555-1234 today for followup.

Cardiac wellness / rehab postdischarge. Unless the patient has another preference, fax this order sheet to Memorial System Cardiac Wellness Center at 555-4321 today for followup.

\section{Infection Control}

Health care providers should be aware that determining if infections are present on admission (as opposed to whether they were hospital-acquired) is becoming increasingly important for reimbursement and infection surveillance. For example, consider ruling out a urinary tract infection when a Foley catheter is first inserted, as follows:

Insert Foley catheter. Collect and submit specimen for urinalysis with culture and sensitivity, if indicated.

\section{Reference Information}

References can be placed on the reverse side of paper orders, or a link to pertinent information may be inserted into electronic orders. Examples of reference information include:

- A list of formulary medications: e.g., ACEI, ARB, beta-blockers. (CHF and AMI orders)

- A list of pertinent core measures and "best practice."

- Antibiotic usage recommendations for pneumonia, orthopedic surgery patients, et al.

- Recommended treatment algorithms for sepsis, stroke, chest pain, et al. 


\section{Attachments to Orders}

Attachments provide additional printed information or forms that are specific to the orders. In the electronic environment, there may be a link to educational materials and information within the information system. ${ }^{20}$ Examples of attachments include specific consent forms and patient education sheets for the nurse to provide to the patient. Attaching these types of documents to orders helps save storage space on the nursing units, and the information may be updated in tandem with the orders.

\section{Other Tools}

In an electronic environment, physician orders can offer automated support through links to research, literature, regulatory standards, and treatment algorithms. Advances in information systems can also compare orders against dosing standards, check for allergies or adverse drug reactions, perform drug-laboratory value and drug-drug interaction checks, and warn about potential errors of omission (e.g., failure to request a partial thromboplastin time [PTT] after ordering HEPARIN) in real time.

\section{"Alert Fatigue"}

Alerts, reminders, references, and attachments are helpful and timely job tools that assist with proper care, but they should not become intrusive or hamper the work process. Although they can be quite beneficial, care must be taken to ensure that reminders and alerts are not overused. "Alert fatigue" can occur in both the paper and computer environments, when caregivers start ignoring bothersome and inappropriate aids. ${ }^{21}$

\section{Enforcement}

Gaining control over preprinted paper orders within a hospital setting can be a challenge. Quite often, physicians create paper orders on their home computers. Frequently, old orders are hoarded, copied, and distributed from nursing units. These unreviewed orders show up suddenly on patient charts with confusing directions, outdated medications, unapproved abbreviations, conflicting instructions, poor legibility, and even letterhead paper from other hospitals. CPOE eliminates many of these issues.

Managing preprinted physician orders on paper includes limiting the number of copies that can be requested from the print shop at any one time (e.g., 25 copies or a 2-week supply). This helps to ensure that old orders are not still in use for months after changes have been made (e.g., waiting until current floor stock of previous form is depleted). Placing blank physician orders on copying machines should be prohibited. (Copying machines are unable to adequately copy barcodes, which disrupts scanning into an electronic record.) Nursing departments can print copies directly from the print shop intranet site until requested print shop copies are delivered.

Our clinical "best practice" (CBP) committee meets for 1 hour monthly to determine and develop order criteria and review existing and new physician orders. The ability and authority to modify orders has been limited to this committee only. The CBP committee also reviews current 
literature and research as it pertains to, and can be integrated into, physician orders. Depending on the orders being reviewed, attendance or input at these meetings may be requested by any clinical area of the hospital-e.g., pharmacy, case management, various physicians, emergency medicine, Joint Commission coordinator, patient safety officer, nursing, dietary, admissions, birth care, unit secretary, radiology, laboratory, stroke coordinator, rehabilitation.

Each reviewed order (along with CBP recommendations for changes) is forwarded to the authoring physician for final approval. A brief list of the order criteria created by CBP is also provided to the physician for reference (see Appendix). Final approval by the physician is required before any modified order can be implemented.

The CBP committee names or titles each order in a standardized manner to simplify locating specific orders from the files or print shop. For example, an order from a particular physician might be named: "Dr. Black Post-op Pacemaker Orders 0907.” This title indicates the name of the physician; the type of order (e.g., pre-op, post-op, admission, discharge); the procedure or diagnosis; and the date last approved. Orders used by a specific group of physicians may be named with the group name first (e.g., "Riverside Vascular Post-op AAA Surgery Orders 0807"). Orders used by a diverse group of practitioners may be named, "Pneumonia ICU Admission Orders 0807.”

The CBP also reviews orders (and any associated references, information, alerts, or attachments) on a routine basis to ensure that they reflect current "best practice" and process.

\section{Conclusion}

Whether in paper or electronic format, well developed physician orders have the ability to affect and help with a multitude of concerns within health care today. Furthermore, preprinted physician orders have the potential to benefit all patients and disciplines. These orders do not require new technology (although they might use it), and once defined, they are low in cost and simple to use. However, maintaining orders in accordance with "best practice" does require a fair amount of vigilance and routine reviews. Perhaps the best advantages of preprinted physician orders lie in their ability to modify physician practice, guide care decisions, provide a comprehensive perspective, and readily adjust to changes.

CPOE may decrease errors and improve quality, but concerns regarding their high implementation cost, operational disruption, and return on investment have proven a major barrier to immediate and widespread adoption throughout the health care industry. ${ }^{22,23}$ Fortunately, during this transitional phase of information management, we have an opportunity to share many of the beneficial aspects of paper and electronic formats of physician orders.

Writing good preprinted physician orders is both an art and a science that requires a team approach. When well designed, these orders integrate pertinent reminders, safety measures, and "best practice" into a just-in-time process. Whether in an electronic or paper format, preprinted physician orders can transform evidence-based knowledge into practice. As such, they have the potential to influence good practice and promote patient safety through clearly written communications. 


\section{Acknowledgments}

We extend special thanks and our appreciation to Sue Cole, RN CPHQ; Tatiana Kosyak, RPh; and Jerry Hood, RPh.

Address correspondence to: Barbara Duffy, RN, LHRM, MPH, Florida Hospital Ormond Memorial, c/o Performance Improvement, 875 Sterthaus Avenue, Ormond Beach, FL 32174; email: duffy@cfl.rr.com.

\section{References}

1. The Joint Commission. Facts about ORYX® for hospitals, core measures and hospital quality measures. Available at: www.jointcommission.org/NewsRoom/PressKits/Ann ualReport/ar_facts_oryx.htm. Accessed February 5, 2008.

2. Eslami S, Abu-Hanna A, de Keizer NF. Evaluation of outpatient computerized physician medication order entry systems: A systematic review. J Am Med Inform Assoc 2007; 4: 400-406.

3. The Joint Commission. 2007 hospital/critical access hospital national patient safety goals. Available at: www.jointcommission.org/PatientSafety/NationalPatie ntSafetyGoals/07_hap_cah_npsgs.htm. Accessed February 5, 2008.

4. Institute for Safe Medication Practices. Let's get our fax straight! Available at: www.ismp.org/Newsletters/acutecare/articles/1998031 1.asp?ptr=y. Accessed February 5, 2008.

5. McCoy L. Look-alike, sound-alike drugs review: Include look-alike packaging as an additional safety check. Jt Comm J Qual Patient Saf 2005; 31: 47-53.

6. Institute for Safe Medication Practices. It's time for standards to improve safety with electronic communication of medication orders. Available at: www.ismp.org/Newsletters/acutecare/articles/2003022 0.asp?ptr=y. Accessed February 5, 2008.

7. Nurse Advise-err. ISMP Medication Safety Alert. 2007; 5: 1-3.

8. U.S. Food and Drug Administration. Medication errors. Available at: www.fda.gov/cder/drug/MedErrors/default.htm. Accessed February 5, 2008.

9. U.S. Food and Drug Administration, Center for Drug Evaluation and Research. Medication errors name differentiation project. Available at: www.fda.gov/cder/drug/MedErrors/nameDiff.htm. Accessed February 5, 2008.
10. Institute for Safe Medication Practices. “Looks” like a problem: Ephedrine - epinephrine. Available at: www.ismp.org/Newsletters/acutecare/articles/2003041 7_2.asp?ptr=y. Accessed February 5, 2008.

11. Joint Commission International Center for Patient Safety. Look-alike, sound-alike medication names. Available at: www.jcipatientsafety.org/fpdf/Presskit/PSSolution1.pdf. Accessed February 5, 2008.

12. American Medical Association. Health literacy: Help your patients understand directions. Available at: www.amaassn.org/amednews/2004/05/10/edsa0510.htm. Accessed February 5, 2008.

13. Kucher N, Koo S, Quiroz R, et al. Electronic alerts to prevent venous thromboembolism among hospitalized patients. New Engl J Med 2005; 352: 969-977.

14. Ozdas A, Speroff T, Waitman LR, et al. Integrating "best of care” protocols into clinicians' workflow via care provider order entry: Impact on quality-of-care indicators for acute myocardial infarction. J Am Med Inform Assoc 2006; 13: 188-196.

15. Garg AX, Adhikari NK, McDonald H, et al. Effects of computerized clinical decision support systems on practitioner performance and patient outcomes. JAMA 2005; 293: 1223-1238.

16. Dexter PR, Perkins SM, Maharry KS, et al. Inpatient computer-based standing orders vs. physician reminders to increase influenza and pneumococcal vaccination rates. JAMA 2004; 292: 2366-2371.

17. Bates WB, Kuperman GJ, Wang S, et al. Ten commandments for effective clinical decision support: Making the practice of evidence-based medicine a reality. J Am Med Inform Assoc 2003; 10: 523-530.

18. Institute for Safe Medication Practices. Action needed to prevent dangerous heparin-insulin confusion. Available at: www.ismp.org/Newsletters/acutecare/articles/2007050 3.asp?ptr=y. Accessed February 8, 2008. 
19. Dexter PR, Perkins S, Overhage JM, et al. A computerized reminder system to increase the use of preventive care for hospitalized patients. New Engl J Med 2001; 345: 965-970.

20. Rosenbloom ST, Geissbuhler AJ, Dupont WD, et al. Effect of CPOE user interface design on user-initiated access to educational and patient information during clinical care. J Am Med Inform Assoc 2005; 12: 458-473.

21. Cohen M, Smetzer J. Do not miss important computer alerts. Hosp Pharm 2007; 42: 396-399.
22. Kaushal R, Jha AK, Franz C, et al. Return on investment for a computerized order entry system. J Am Med Inform Assoc 2006; 13: 261-266.

23. Kuperman GJ, Gibson RF. Computer physician order entry: Benefits, costs, and issues. Ann Intern Med 2003; 139: 31-39. 


\section{Appendix}

\section{Creating Preprinted Physician Orders for Clinical "best practice" Review}

\section{Criteria for consideration when creating or revising preprinted physician orders}

\begin{tabular}{ll|l}
\hline \multicolumn{1}{c|}{ Content and Format } & Yes \\
\hline 1 & Orders reflect current "best practice" & \\
\hline 2 & Orders are created in Arial 10- or 12-point font & \\
\hline 3 & Orders do not contain unapproved abbreviations & \\
\hline 4 & Orders do not contain confusing symbols (e.g., < and >) & \\
\hline 5 & Blanket orders are not used. (i.e., Resume home meds). & \\
\hline 7 & Order contains space for physician signature, physician ID \#, and date & \\
\hline 8 & $\begin{array}{l}\text { Admission orders include "Admit as inpatient," "Outpatient," or "Observation Status," } \\
\text { as appropriate }\end{array}$ & \\
\hline 9 & $\begin{array}{l}\text { Orders are single-sided (Reverse side of sheet should contain additional information or } \\
\text { references only) }\end{array}$ & \\
\hline & & Yes \\
\hline 10 & Abbreviations, when used, are kept to a minimum & \\
\hline 11 & Medication orders are not numbered & \\
\hline 12 & Medication orders contain drug name, dose, route, and frequency & \\
\hline 13 & If multiple routes are listed, order contains criteria to determine which route to use & \\
\hline 14 & When possible, order contains dose written as mg, and not as tablets or mL & \\
\hline 15 & Order does not contain multiple ranges & \\
\hline 16 & Order contains indication for PRN medications & \\
\hline 17 & Time frame is written for IV bolus / IV push orders & \\
\hline 18 & Generic and trade names (if applicable) of medication are used & \\
\hline
\end{tabular}

Actions by the Clinical "Best Practice" Committee (CBP) may include:

\begin{tabular}{l|l}
\hline & Arranging presentation of orders according to standardized format \\
\hline & Adding indications of regulatory / Performance measures, etc. \\
\hline & Adding DVT prophylaxis, vaccination status, smoking counseling, patient education, etc \\
\hline & Adding safety alerts and reminders as appropriate \\
\hline & Including computer software-specific language for order entry \\
\hline & Naming the orders according to standardized process to simplify order search / identification \\
\hline & Review of orders for clarity of intent \\
\hline
\end{tabular}

CBP may contact the physician before modifying an order and will request final approval by the authoring physician before implementing or distributing orders. $\quad 1207$ 